Science, Technology and Development 34 (3): 140-146, 2015

ISSN 0254-6418 / DOI: 10.3923/std.2015.140.146

(C) 2015 Pakistan Council for Science and Technology

\title{
Impact of Drying Methods and Extraction Solvents on the Steroidal Saponians Content of Tibullus terresteris Grown in the Peshawar Valley of Khyberpakhtunkhwa, Pakistan
}

\author{
${ }^{1}$ Muhammad Hanif, ${ }^{1}$ Mansoor Khan Khattak, ${ }^{1}$ Masood Ur Rehman, ${ }^{1}$ Muhammad Ramzan, \\ ${ }^{1}$ Muhammad Amin, ${ }^{1}$ Muhammad Aamir, ${ }^{2}$ Syed Awais Ali, ${ }^{1}$ Shaiza Sheikh Sher, ${ }^{1}$ Hafizullah, ${ }^{1}$ Saqib Khan, \\ ${ }^{1}$ Muhammad Saeed, ${ }^{1}$ Abdullah Khan and ${ }^{1}$ Muhammad Saqlain \\ ${ }^{1}$ Department of Agricultural Mechanization, Faculty of Crop Production Sciences, \\ The University of Agriculture Peshawar, Pakistan \\ ${ }^{2}$ Department of Food Science and Technology, Faculty of Nutrition Sciences, \\ The University of Agriculture Peshawar, Pakistan
}

\begin{abstract}
The experiments were conducted to see the impact of drying methods and extraction solvents on the yield of steroidal saponins of Tribulus terrestris. The plant was dried by three different drying methods namely, solar collector drying, open sun drying and shade drying. After drying different levels (25-100\%) of extracting solvent in the form of ethanol, methanol and distilled water were used for extraction. Soxhlet apparatus was used for extraction, while the gas chromatography apparatus was used in the experiment for detecting steroidal saponins in Tribulus terrestris. After extraction, four saponins identified were Tigogenin, Gitogenin, Hecogenin and Neohecogenin. The maximum yield of $61.2 \%$ was recorded for flat plate solar drying with $75 \%$ ethanol solution, followed $49.5 \%$ in shade drying with the same extraction solvent level. The lowest value of $3.1 \%$ yield was recorded for distilled water with open sun drying method. It was concluded that Both the drying methods and extraction solvent have a direct effect on the yield of steroidal saponins extracted from Tribulus terrestris. A maximum yield of almost $60 \%$ saponins may be achieved, if Tribulus terrestris is dried using a flat plate solar collector and extorted with 75\% ethanol solution using GC-MS technique. Open sun drying minimizes saponins in Tribulus terrestris, while distilled water is the worse extracting solvent for extraction of steroidal saponins from Tribulus terrestris.
\end{abstract}

Key words: Flat plate solar collector, gas chromatography, soxhlet extortion, steroidal saponins, Tribulus terrestris

\section{INTRODUCTION}

Tribulus terrestris (Zygophyllaceae) known as puncture vine or devil weed is herbaceous and mat forming plant used for centuries, as a source of biomedicines. It is the most common Rabi crop weed found in warm, dry tropics of the world. The early Egyptians, Babylonians, Samarians, Greeks, Romans, Indians and Chinese all used Tribulus terrestris in their system of medicines. It posses special nutritional and healing powers that often go beyond chemotherapy (Hashim et al., 2014). It contains a number of steroidal saponins and is used for the treatment of many diseases like infertility, cardiac, muscle building, conditioning and treatment of some other microbial diseases (Al-Bayati and Al-Mola, 2008). Besides saponins it also contains flavonoids, alkaloids, lignin amides and cinnamic acid amides. The amount of metabolites depends on the part of the plant, which is used. The fresh juice of the aqueous extract of the whole plant contains inorganic nitrates, most likely potassium nitrate (Huang et al., 2002). The fruit of Tribulus terrestris is rich with alkaloid, resin, fat, ascorbic acid, minerals and essential oils. It also contains a rich amount of iron and zinc, thus used for infertility in men and women. The difference in saponins content and composition is observed in different regions of the world (Bedir et al., 2002; Chen et al., 2013).

To extract the saponins from the plant, it is dried in either open sun or shade with high air velocities and after drying the saponins are extracted using different levels of ethanol and methanol as steroidal saponins are highly polar in nature (Ganzera et al., 2001). During to sun or shade drying, about $20-30 \%$ of saponins are lost due to the uncontrolled drying environment and degradation by direct Ultraviolet light rays (Sisto et al., 2012). The present research aims to dry Tribulus terrestris in a

Corresponding Author: Muhammad Hanif, Department of Agricultural Mechanization, Faculty of Crop Production Sciences, The University of Agriculture Peshawar, Pakistan Tel: +923339049552 
controlled drying environment using flat plate solar collector and study the effect of different drying methods, i.e., conventional including, open sun and shade drying and controlled convective drying by using solar collector, on the percentage of overall extracted saponins. The novelty of the research is to find the amount and composition of different saponins in the Tribulus terrestris grow in the Peshawar valley of the Khyber Pakhtunkhawa province of Pakistan.

\section{MATERIALS AND METHODS}

Plant materials: Tribulus terrestris (puncture vine) is the local and very common weeds of Peshawar Valley found in Rabi crops locally called as Markondi plant. Only ripe and good quality, weeds free from any spot, damage or foreign material was collected for the experiment (Sun et al., 2003; Muthana, 2007) from the Newly Developmental Farm of the Agricultural University of Peshawar KPK, Pakistan.

Experimental setup: The experiment consists of three different drying setups. Drying by solar collector which is the main setup as shown in Fig. 1, consists of an indirect forced convection solar dryer with a flat plate solar collector, a circulation fan and a cabinet dryer. The drying was done by the procedure given by Hanif et al. (2013). The second setup as shown in Fig. 2 was to dry the plant

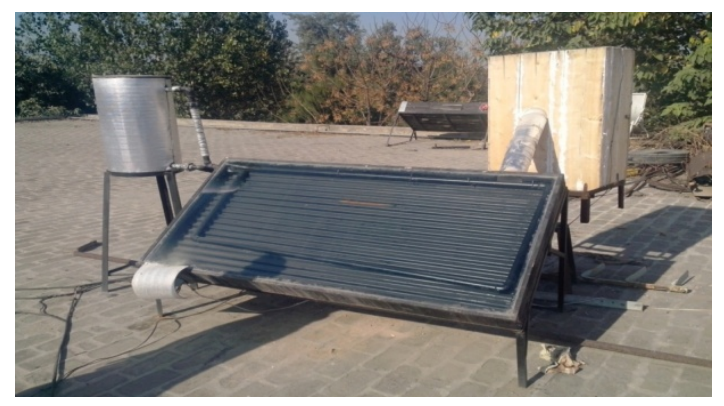

Fig. 1: General view of the solar dryer trays for drying purpose in the solar collector's dryer

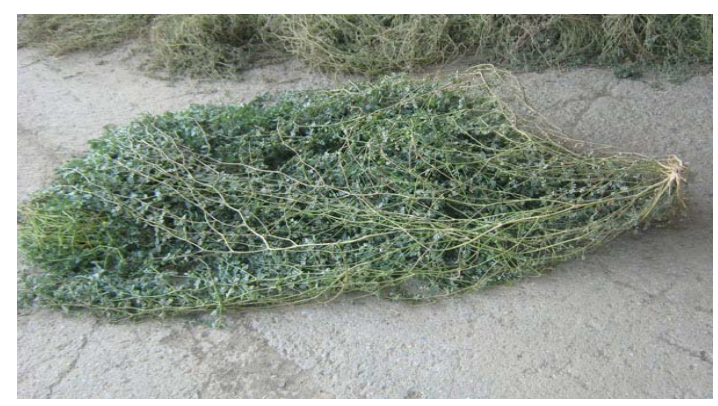

Fig. 2: Open sun drying of Tribulus terrestris parts in open sun. The plant material was spread over the concrete floor on an area of $1.10 \mathrm{~m}^{2}$ and dried in the sun (Kostova et al., 2002; Saleh et al., 1982). The third setup as shown in Fig. 3 was drying the plants in a shade under a velocity of $3.11 \mathrm{~m} \mathrm{sec}^{-1}$. The drying was performed in a dark room. Plant materials were dried until the moisture content reached $<5 \%$. The data of moisture in the plant were recorded after each hour of drying (Tomowa et al., 1974; Kostova and Dinche, 2005).

Extraction of essential volatiles and GC-MS analysis: Soxhlet apparatus (Fig. 4) was used for extraction was considered as the reference technique. Exhaustive Soxhlet extraction was performed using a classical Soxhlet apparatus with an accurate measure of $1.0 \mathrm{~g}$ of Tribulus terrestris powder for $24 \mathrm{~h}$. Extraction was performed with different levels of ethanol, methanol $(25,50,75,100 \%)$ and a single dose of distilled water as the extracting solvent. The extraction was conducted for $8 \mathrm{~h}$ for three times. Each time, the prior extract was removed and then $50 \mathrm{~mL}$ fresh ethanol was added. Finally, all the three extracts were combined and evaporated under vacuum. The extraction yield of total four saponins was defined as follows (Neychev et al., 2007):

$$
\text { Yield }(\%)=\frac{\text { Mass of saponin sinone }- \text { step extraction solution }}{\text { Sum of the mass of saponins in sample }} \times 100
$$

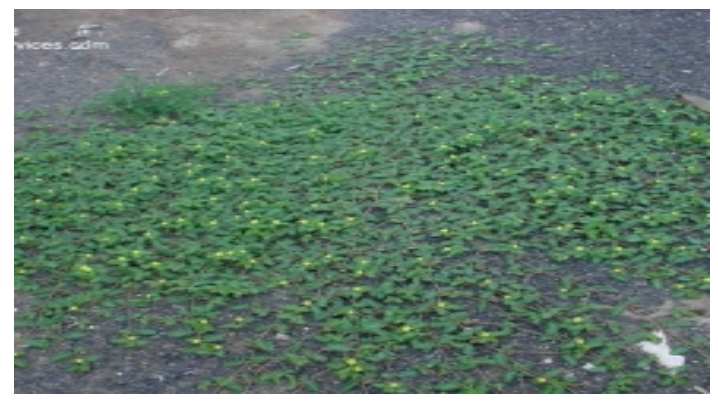

Fig. 3: Shade drying of Tribulus terrestris

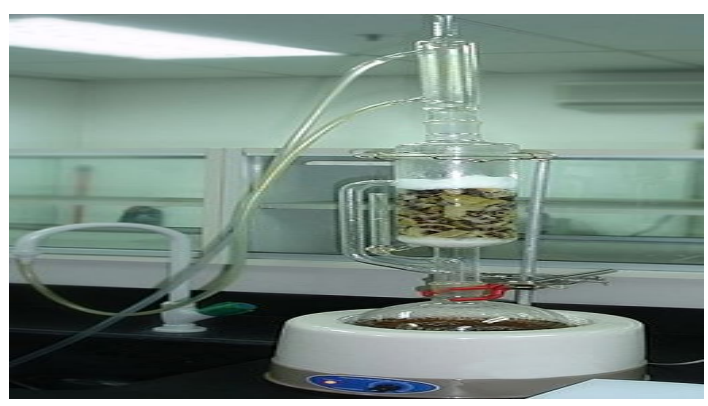

Fig. 4: Soxhlet apparatus used for extraction of volatiles in Tribulus terrestris 


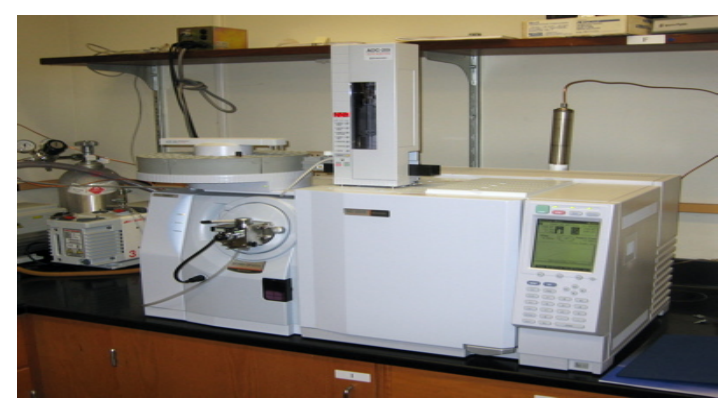

Fig. 5: Gas chromatography apparatus used in the experiment for detecting steroidal saponins in Tribulus terrestris

The mass of saponins in the extraction solution (one-step extraction) was analyzed by GC-MS (Fig. 5). The sum of the mass of saponins in the sample was determined by analysis of the total extraction solutions by continuous Soxhlet extraction for $24 \mathrm{~h}$. Column flow was volumetric at $1.50 \mathrm{~mL} \mathrm{~min}^{-1}$ using ultra purified helium (499.999\%) as the carrier gas. The splitless injection port was maintained at $250^{\circ} \mathrm{C}$. The Injection was in split mode with a split ratio of 40:1. The transfer line temperature was set at $280^{\circ} \mathrm{C}$. The mass analyzer was set at $70 \mathrm{eV}$, electron impact source temperature of $220^{\circ} \mathrm{C}$. Electron-multiplier voltage of $1588 \mathrm{mV}$ and solvents delay of three minutes. All data were obtained by collecting the full-scan mass spectra within the scan range of 50-600 amu. The temperature program was as follows: initially from $200-280^{\circ} \mathrm{C}$ at ramp rate of $25^{\circ} \mathrm{C} \mathrm{min}^{-1}$ and from $270-280^{\circ} \mathrm{C}$ at ramp rate of $1^{\circ} \mathrm{C} \min ^{-1}$ (Xu et al., 2008, 2010a).

\section{RESULTS AND DISCUSSION}

Meteorological data: The meteorological data on the site are given in Fig. 6. The ambient temperature (Ta) varied between 27 and $40^{\circ} \mathrm{C}$ during the experimental period (May, 2014). The temperature for the open sun system remain the same as the ambient temperature, while for the shade it is $2 \%$ less than that of ambient. The solar collector allowed increasing the air temperature (Tout) up to $27^{\circ} \mathrm{C}$ above the ambient temperature, depending on the mass air flow rate and mainly of the solar flux on a tilted collector. During the complete drying period, the solar flux on a tilted collector remained above $550 \mathrm{~W} \mathrm{~m}^{-2}$, with a peak value of $712 \mathrm{Wm}^{-2}$ at around (12.00 noon). The temperature and relative air humidity of the drying air at the inlet of the drying chamber were also registered, which are presented for some runs. The drying air temperature at the inlet of the drying chamber kept at the

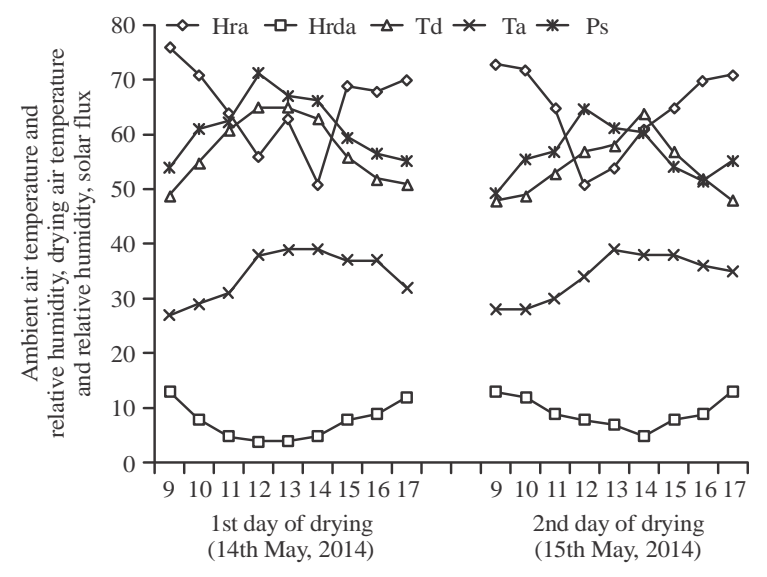

Fig. 6: Meteorological data in Peshawar (Pakistan). Solar flux on a tilted collector, Relative humidity and temperature of the drying air recorded in May 2014

values of the interval $50-64^{\circ} \mathrm{C}$ with variations of $\pm 1^{\circ} \mathrm{C}$. The ambient relative humidity varies from $51-76 \%$ with variations $\pm 2 \%$. The drying temperature is raised to give a lower relative humidity of drying air. The relative humidity of the drying air at the inlet of the dryer is less than $5 \pm 2 \%$. The lower the relative humidity of drying air supplied to the drying chamber is the better the drying rate, as the less humid air can tend to pick up moisture more quickly and easily from the product surface than the more humid air. In addition to that, Demir et al. (2007) stated that a solar dryer, which provides a temperature in the range of $45-65^{\circ} \mathrm{C}$ and a relative humidity of drying air less than $20 \%$ is favorable for drying any agricultural product. In this study, the solar dryer took only $9 \mathrm{~h}$ for reducing the moisture content of white mulberry inside the dryer from $76-9 \%(w b)$. During the experiment, the drying air passing through the product at a mass flow rate of $1.5 \mathrm{~kg} \mathrm{~min}{ }^{-1}$ with the accuracy of $\pm 0.1 \mathrm{~m} \mathrm{sec}^{-1}$, whereas the relative humidity is below $10 \%$ and the temperature varies between 50 and $65^{\circ} \mathrm{C}$.

Drying curves: The drying curves by the three setups is shown in Fig. 7. The graph shows that flat plate solar collector took $9 \mathrm{~h}$ to dry the plant material, convective shade drying took 19 , while the conventional sun drying system took $27 \mathrm{~h}$ of drying period to dry the plant. The drying time is reduced from 27-9 h, which showed that flat plate solar collector save more time of drying as compared to conventional drying of Tribulus terrestris by the open sun drying system. The results are in accordance with the findings of Hanif et al. (2013), who reported that flat plate solar drying systems facilitates drying, increase quality and reduce drying time. These results are also in accordance with the findings of Sisto et al. (2012). 
Sci. Technol. Dev., 34 (3): 140-146, 2015

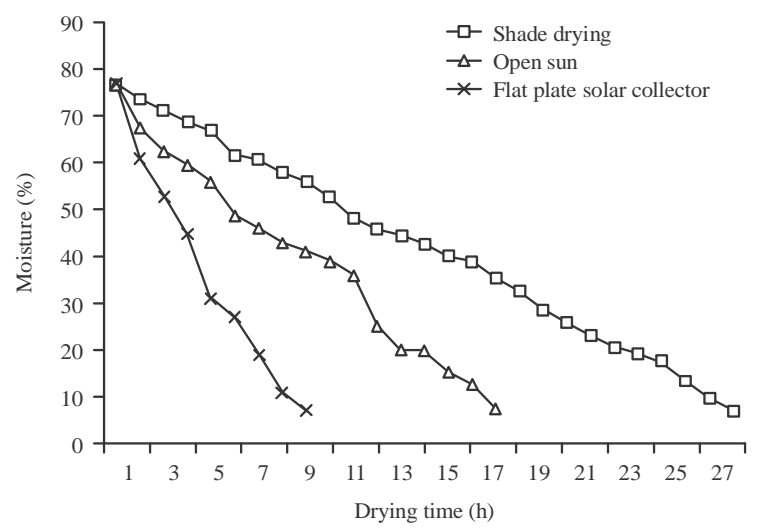

Fig. 7: Drying curves of the three drying setup of Tribulus terrestris

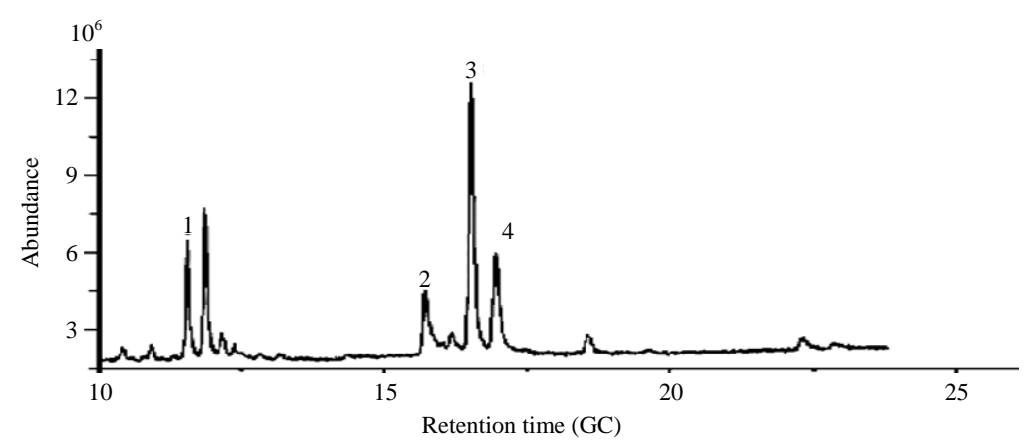

Fig. 8: Total ion mass chromatogram of Tribulus terrestris by GC-MS. Representing 1. TG, 2. GG, 3. HG and NG

Identification of saponins: With the reported chromatographic conditions (Li et al., 2009) a capillary column of HP-5MS was particularly useful for the separation of saponins. Absolute separation of the analytes was attained in 22 min (Fig. 8). The Total ion mass chromatogram of saponins obtained was differentiated by the manifestation of Molecular Ions (M1) and an ion at the base peak. Four different steroidal saponins from the extracts were identified, who targets matched to $99 \%$ fit with the standard steroidal saponins provided by the Pakistan Academy of Sciences (PAS).

Recognition of steroidal saponins in the analytes was based on the relationship of retention time and mass spectra to the genuine compound. Identification of the four saponins was, according to the molecular weight and standard spectra of the Standards. The four saponins identified are; 1 . Tigogenin (TG-M+416 amu), 2. Gitogenin (GG-M+432 amu), 3. Hecogenin (HG-M+430 amu) and 4. Neohecogenin (NG-M+430 $\mathrm{amu}$ ). The structure of all the four saponins is as shown in Fig. 9. The formulae of each structure of four steroidal saponins identified by GC-MS in Tribulus terrestris is given in Table 1. The same type of saponins were resulted from the extracts of Tribulus terrestris used in experiments by Bedir et al. (2002), Chen et al. (2013), Ganzera et al. (2001) and Huang et al. (2002).

The impact of extraction solvent and drying methods on the yield of steroidal saponins extracted from Tribulus terrestris is given in Table 2. The statistical analysis of the data showed that both the factors have a significant effect $(\alpha<0.001)$ on the extracted yield of steroidal saponins from Tribulus terrestris. The maximum yield of $61.2 \%$ was recorded for flat plate solar drying with $75 \%$ ethanol solution, followed $49.5 \%$ in shade drying with the same extraction solvent level. The lowest value of 3.1\% yield was recorded for distilled water with open sun drying method. The means comparison of drying methods showed that highest yield of $32.0 \%$ was recorded for flat plate solar drying system followed by shade drying with a value of $28.5 \%$, while the lowest yield of $25.5 \%$ was recorded for the open sun drying system. Similarly the means comparison of extracting solvent solution levels showed that highest yield of 52.3\% was recorded for ethanol $75 \%$ followed by $44.2 \%$ in $100 \%$ ethanol. The lowest yield of $3.9 \%$ was recorded for distilled water. It is clear from the results that saponins 
Sci. Technol. Dev., 34 (3): 140-146, 2015
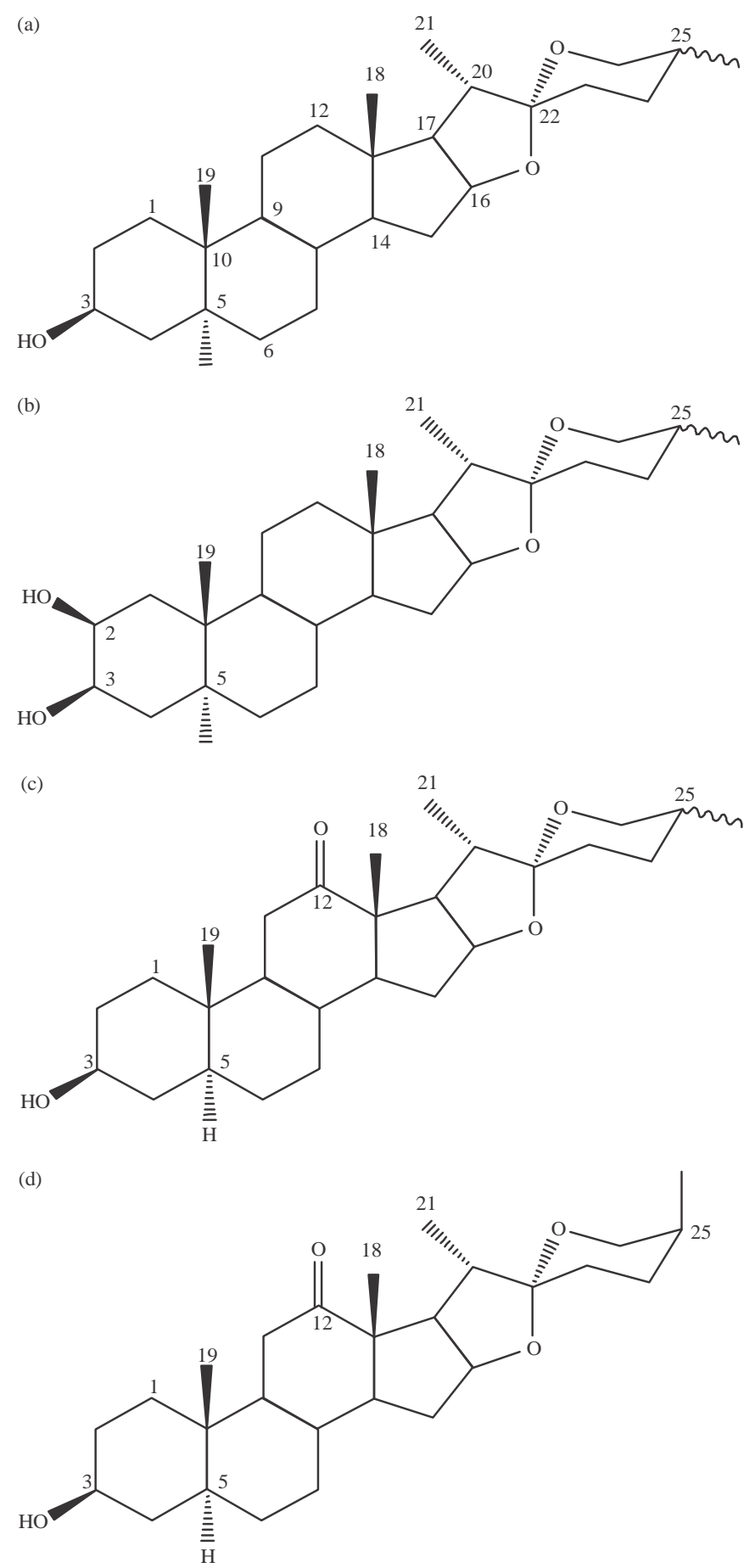

Fig. 9: Four steroidal saponins extracted from Tribulus terrestris found in the Peshawar Valley of KPK. Pakistan, (a) Tigogenen (b) Gitogenin (c) Hecogenin and (d) Neohecogenin

Table 1: Formulae of each structure of four steroidal saponin identified by GC-MS in Tribulus terrestris

\begin{tabular}{|c|c|c|c|c|c|c|}
\hline Peak No. & $\begin{array}{l}\text { Retention } \\
\text { time (min) }\end{array}$ & $\begin{array}{l}\text { Fit with the } \\
\text { standard (\%) }\end{array}$ & $\begin{array}{l}\text { Name of } \\
\text { steroidal saponin }\end{array}$ & Formula of steroidal saponin & Fraction & $\pm \mathrm{SD}$ \\
\hline 1 & 11 & 99 & Tigogenin (TG) & 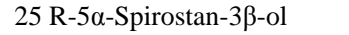 & 13.89 & \pm 1.15 \\
\hline 2 & 15 & 99 & Gitogenin (GG) & 25 R-5 $\alpha$-Spirostan-2 $\alpha, 3 \beta$-diol & 7.82 & \pm 1.01 \\
\hline 3 & 16 & 99 & Hecogenin (HG) & 25 R-5 $\alpha$-Spirostan-12-one & 25.76 & \pm 1.62 \\
\hline 4 & 17 & 99 & Neohecogenin (NG) & 25 S-5 $\alpha$-Spirostan-12-one & 7.93 & \pm 0.91 \\
\hline
\end{tabular}


Sci. Technol. Dev., 34 (3): 140-146, 2015

Table 2: Mean comparison $(\alpha<0.001)$ of drying methods and extraction solvent on the yield of steroidal saponins extracted from Tribulus terrestris

\begin{tabular}{|c|c|c|c|c|}
\hline \multirow[b]{2}{*}{ Extracting solvent levels } & \multicolumn{4}{|c|}{ Drying methods } \\
\hline & Shade drying & Open sun & FPS collector & Mean \\
\hline Ethanol 25 & 17.3 & 13.2 & 19.1 & $16.5^{\mathrm{d}}$ \\
\hline Ethanol 50 & 30.2 & 26.5 & 35.4 & $30.7^{c}$ \\
\hline Ethanol 75 & 49.5 & 46.3 & 61.2 & $52.3^{\mathrm{a}}$ \\
\hline Ethanol 100 & 44.2 & 43.8 & 45.1 & $44.4^{\mathrm{b}}$ \\
\hline Methanol 25 & 22.9 & 20.9 & 23.4 & 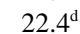 \\
\hline Methanol 50 & 35.2 & 31.0 & 35.9 & $34.0^{c}$ \\
\hline Methanol 75 & 28.7 & 24.1 & 31.2 & $28.0^{\mathrm{d}}$ \\
\hline Methanol 100 & 24.3 & 20.3 & 29.9 & $24.8^{\mathrm{d}}$ \\
\hline Distilled water & 4.5 & 3.1 & 7.2 & $4.9^{\mathrm{e}}$ \\
\hline Mean & $28.5^{\mathrm{a}}$ & $25.5^{\mathrm{b}}$ & $32.0^{\mathrm{a}}$ & \\
\hline
\end{tabular}

are highly polar compounds and their extraction is highly effected by the use of extracting solvent. Ethanol and methanol gave good yields because they are non polar where is the yield was minimum for distilled water because of the polarity effect of the two solvents. These results are in accord with the findings of Kostova and Dinche (2005), Muthana (2007) and Xu et al. (2008, 2010b).

\section{CONCLUSION}

Both the drying methods and extraction solvent have a direct effect on the yield of steroidal saponins extracted from Tribulus terrestris. A maximum yield of almost $60 \%$ saponins may be achieved if Tribulus terrestris is dried using a flat plate solar collector and extorted with $75 \%$ ethanol solution using GC-MS technique. Open sun drying minimizes saponins in Tribulus terrestris is while distilled water is the worse extracting solvent for extraction of steroidal saponins from Tribulus terrestris.

\section{ACKNOWLEDGMENT}

The author acknowledged the help and assistance provided by Yahya Dallo, research associate in the Department of Plant Pathology, Viginia Tech University, USA.

\section{REFERENCES}

Al-Bayati, F.A. and H.F. Al-Mola, 2008. Antibacterial and antifungal activities of different parts of Tribulus terrestris L. growing in Iraq. J. Zhejiang Univ. Sci. B, 9: 154-159.

Bedir, E., I.A. Khan and L.A. Walker, 2002. Biologically active steroidal glycosides from Tribulus terrestris. Pharmazie, 57: 491-493.

Chen, G., L. Su, S.G. Feng, X. Lu, H. Wang and Y.H. Pei, 2013. Furostanol saponins from the fruits of Tribulus terrestris. Nat. Prod. Res., 27: 1186-1190.
Demir, V., T. Gunhan and A.K. Yagcioglu, 2007. Mathematical modelling of convection drying of green table olives. Biosyst. Eng., 98: 47-53.

Ganzera, M., E. Bedir and I.A. Khan, 2001. Determination of steroidal saponins in Tribulus terrestris by reversed-phase high-performance liquid chromatography and evaporative light scattering detection. J. Pharm. Sci., 90: 1752-1758.

Hanif, M., M. Rahman, M. Khan, M. Aamir, M. Ramzan, M. Amin and I.A. Mari, 2013. Impact of drying temperatures and air mass flow rates on the drying performance of a Parabolic Trough Solar Collector (PTSC) used for dehydration of apricots. Emir. J. Food Agric., 25: 418-425.

Hashim, S., T. Bakht, K.B. Marwat and A. Jan, 2014. Medicinal properties, phytochemistry and pharmacology of Tribulus terrestris L. (Zygophyllaceae). Pak. J. Bot., 46: 399-404.

Huang, J.W. S.H. Jiang, C.H. Tan and D.Y. Zhu, 2002. Structural elucidation of three new steroid saponins. Chinese J. Organic Chemis., 22: 917-921.

Kostova, I., D. Dinchev, G.H. Rentsch, V. Dimitrov and A. Ivanova, 2002. Two new sulfated furostanol saponins from Tribulus terrestris. Z. Naturforsch. C, 57: 33-38.

Kostova, I. and D. Dinchev, 2005. Saponins in Tribulus terrestris-chemistry and bioactivity. Phytochem. Rev., 4: 111-137.

Li, T., Z. Zhang, L. Zhang, X. Huang, J. Lin and G. Chen, 2009. An improved facile method for extraction and determination of steroidal saponins in Tribulus terrestris by focused microwave-assisted extraction coupled with GC-MS. J. Sep. Sci., 32: 4167-4175.

Muthana, J.M., 2007. Biological activity of saponins isolated from Tribulus terrestris (Fruit) on growth of some bacteria. Tikrit J. Pure Sci., 13: 101-104.

Neychev, V.K., E. Nikolova, N. Zhelev and V.I. Mitev, 2007. Saponins from Tribulus terrestris L. are less toxic for normal human fibroblasts than for many cancer lines: Influence on apoptosis and proliferation. Exp. Biol. Med. (Maywood), 232: 126-133. 
Saleh, N.A.M., A.A. Ahmed and M.F. Abdalla, 1982. Flavonoid glycosides of Tribulus pentandrus and T. terrestris. Phytochemistry, 21: 1995-2000.

Sisto, M., S. Lisi, M. D'Amore, R. De Lucro and D. Carati et al., 2012. Saponins from Tribulus terrestris L. protect human keratinocytes from UVB-induced damage. J. Photochem. Photobiol. B: Biol., 117: 193-201.

Sun, B., W. Qu and Z. Bai, 2003. [The inhibitory effect of saponins from Tribulus terrestris on Bcap-37 breast cancer cell line in vitro]. Zhong Yao Cai., 26: 104-106, (In Chinese).

Tomowa, M.P., D. Panowa and N.S. Wulfson, 1974. [Steroid saponines and sapogenins. IV. Saponines from Tribulus terrestris]. Planta Med., 25: 231-237, (In German).
Xu, T.H., Y.J. Xu, S.X. Xie, H.F. Zhao and D. Han et al., 2008. Two new furostanol saponins from Tribulus terrestris L. J. Asian Nat. Prod. Res., 10: 419-423.

Xu, Y., Y.H. Liu, T.H. Xu, S.X. Xie and Y.H. Si et al., 2010a. A new furostanol glycoside from Tribulus terrestris. Molecules, 15: 613-618.

Xu, Y.J., T.H. Xu, H.O. Zhou, B. Li and S.X. Xie et al., 2010b. Two new furostanol saponins from Tribulus terrestris. J. Asian Nat. Prod. Res., 12: 349-354. 